\title{
Pigment dispersion in a case of Alport's syndrome
}

\author{
P. D. DAVIES
}

Guy's Hospital, London

The syndrome of hereditary nephritis and perceptive deafness was first recognized by Alport (1927), although reports suggestive of this association date from the latter part of the 18 th century. The syndrome has since been widened to include certain ocular defects, such as lenticonus, microspherophakia, and lens opacities, and about 100 families have been described in the world literature. In recent years there have been several detailed reviews of the syndrome (Perkoff, Nugent, Dolowitz, Stephens, Carnes, and Tyler, 1958; Shaw and Glover, I96I; Crawfurd and Toghill, I968), including one of the ophthalmological findings (Arnott, Crawfurd, and Toghill, 1966). This present report concerns a new family with previously unrecorded ocular defects.

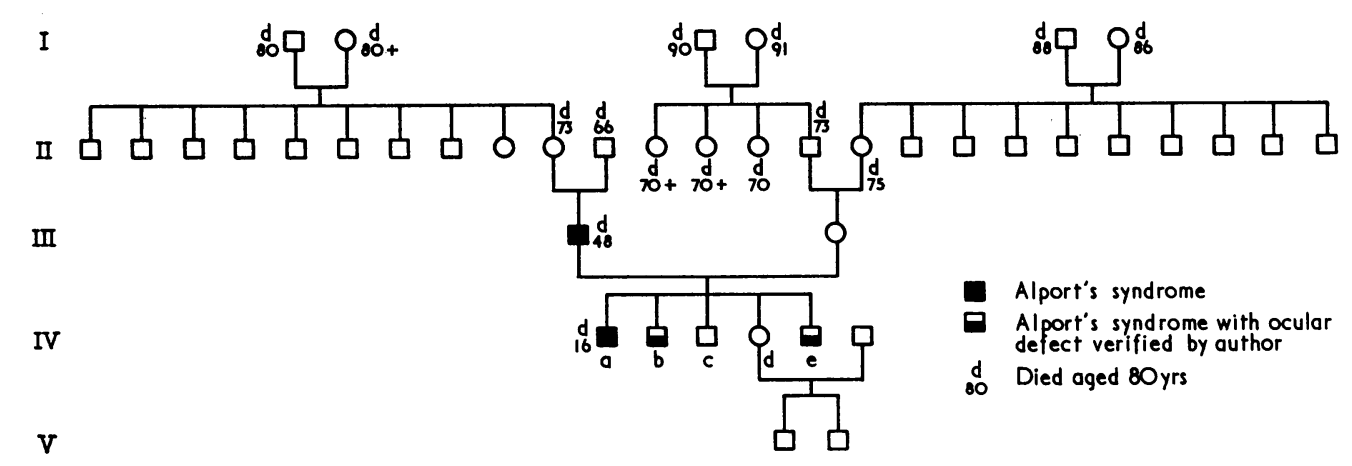

FIG. I Pedigree of family with Alport's syndrome

\section{Case reports}

The last five generations of this family, shown in Fig. I, include affected kindred in Generations III and IV. The two individuals who have been studied in most detail are IVb and IVe, but all surviving descendants of IIIa have been examined and the syndrome excluded.

IVb. This young man aged 25 years was first seen at the renal clinic, to which he had been referred from a provincial hospital for assessment of chronic renal failure and suitability for long-term renal dialysis. His perceptive deafness was first noted at this time and, in addition, the presence of what were thought to be lens opacities completed the diagnostic triad of renal, auditory, and ocular defects that comprises Alport's syndrome. He was subsequently examined in the Eye Department, 
where it was noted that he considered his visual acuity to be normal but that he had been troubled by photophobia for over ro years. Examination revealed the following:

Visual acuity Right 6/18 partly; left 6/24 (corrected).

Pupils These were unusually large at $4.5 \mathrm{~mm}$. diameter in bright summer daylight, but reacted briskly to stimuli although the magnitude of the response was poor. It was found that mydriatics (gutt. homatropine and cocaine, cyclopentolate hydrochloride I per cent., phenylephrine hydrochloride Io per cent.) produced a rapid and profound mydriasis so that the lens zonule could be easily seen with a loupe. The irides were markedly atrophic and this was thought to be the explanation of the above findings.

Corneae A fine dusting of pigment granules was present on the posterior corneal surface; this was more dense inferiorly and, in addition to this general pigment dusting of the endothelium, welldefined Krukenberg spindles were present in both eyes. Gonioscopy revealed both angles to be wide open but with a large quantity of pigment on the trabecular meshwork. The ocular tensions were normal (right $15 \mathrm{~mm}$. $\mathrm{Hg}$, left $16 \mathrm{~mm}$. $\mathrm{Hg}$ ). Provocative tests for glaucoma (waterdrinking, dark-room, and mydriatic tests) gave negative results.

Lens A well-marked bilateral anterior lenticonus was present and, on the roughened anterior lens capsule that corresponded with the lenticonus, there were considerable pigment deposits (Fig. 2); these were also present in the intersections of the zonular attachments to the lens capsule.

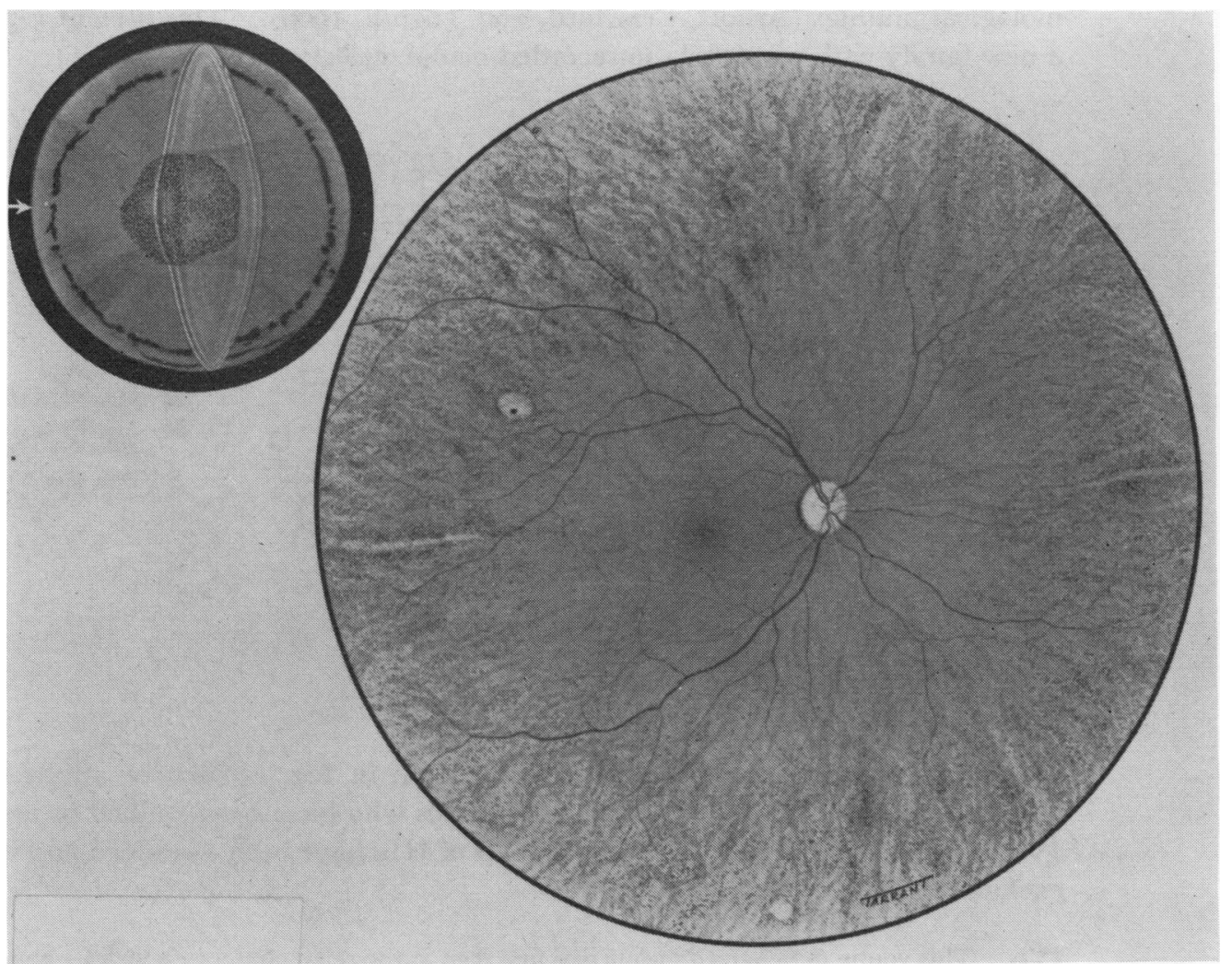

FIG. 2 Patient IVb. Painting of lens, showing pigment deposits on anterior lenticonus and among attachments of zonule to posterior lens capsule

FIG. 3 Patient IVb. Painting of fundus, showing numerous small pigment deposits at periphery of retina 
Fundi The retina of each eye was thinned peripherally with numerous small aggregations of pigment extending posteriorly behind the equator (Fig. 3). The visual fields and colour discrimination were normal, as were the electroretinogram (ERG) and the electro-oculogram (EOG) at the first examination in June, 1968 . Re-examination some 15 months later in October, 1969 , showed that the fundus changes described above extended further posteriorly and that the visual acuity had deteriorated to right $6 / 36$ and left 6/6o (corrected). The visual fields, colour discrimination, and EOG remained normal but the ERG was abnormal with an absent " $b$ " wave, typical of tapeto-retinal degeneration (Fig. 4). In view of the discrepancy between the ERG and the visual fields, the former was repeated in late November, 1969, and on this occasion the " $b$ " waves, although quantitatively in the lower range of normal, were qualitatively normal. In view of the equivocal results obtained with the ERGs, this patient cannot at this stage be regarded as having a tapeto-retinal degeneration.

FIG. 4
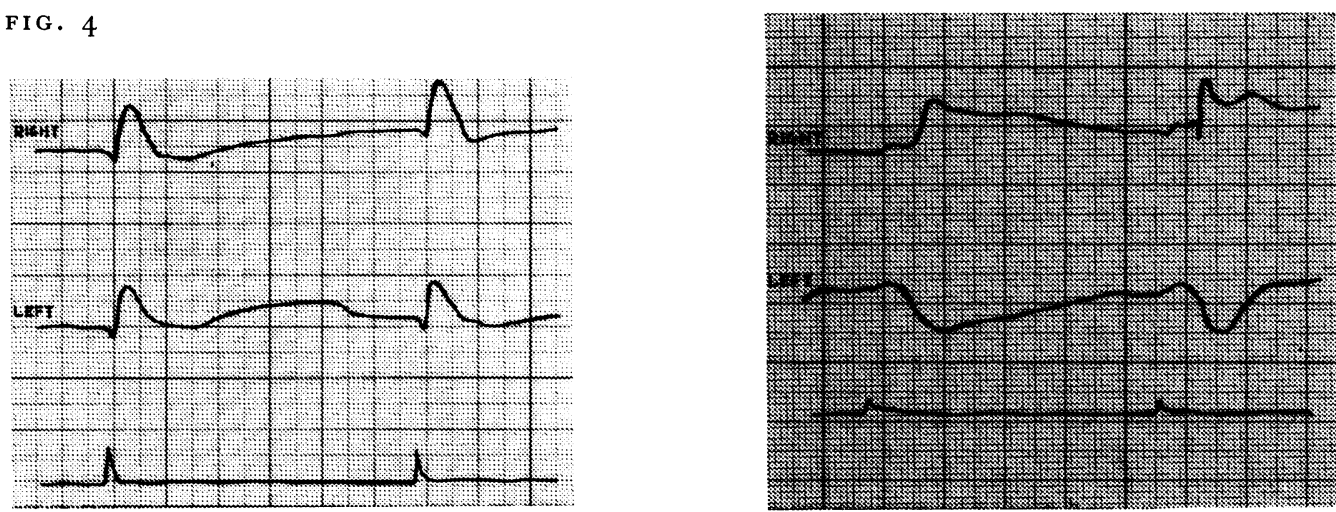

July 5, 1968. Scotopic ERG at I 3 min.

Calibration $20 \mathrm{~mm} .=500 \mu \mathrm{v}$

a-wave $37 \cdot 5 \mu v$ normal, b-wave $225 \mu v$

October 2, 1969. Scotopic ERG at 10 min.

Calibration $20 \mathrm{~mm} .=500 \mu \nu$

$a$-wave minimal, $b$-wave subnormal

EOG, Right 192 per cent., Left 180 per cent.

EOG, Right I 50 per cent., Left I 70 per cent.

IVe. A boy aged 15 years was first seen during the general survey of this family. His general health was described as excellent and he had no symptoms referable to his eyes. Examination revealed:

Visual acuity $\quad$ Right $6 / 9$; left $6 / 7 \cdot 5$ (corrected).

Pupils Normal in size and response.

Media and fundi Both lenses showed a mild anterior lenticonus, but there was no evidence of pigment dispersion as in his elder brother ( $\mathrm{IVb})$. Fundus examination showed minimal peripheral retinal thinning only.

General examination A mild perceptive deafness was noted and confirmed by audiometry. Urine analysis revealed an albumin content of $\mathrm{I}$ g./l., but no casts were seen. Blood chemistry and clearance studies were normal.

IIIa and IVa. Both these kindred, the father and elder brother respectively of the two affected males described above, died of malignant hypertension and its sequelae. Both were known within the family to be deaf and, although they are not recorded as having any ocular abnormality, there is little doubt that they also suffered from Alport's syndrome. 


\section{Discussion}

(I) OCULAR DEFECT

The pigment granules found to be present on the posterior corneal surfaces, anterior $\stackrel{\vec{F}}{\stackrel{\vec{S}}{\rightarrow}}$ iris surfaces, and on both anterior and posterior lenticular surfaces, together with the dense trabecular pigment of patient $I V b$, appear to have resulted from the liberation of $\frac{\bar{\partial}}{\overline{\frac{D}{}}}$ pigment from the atrophied iris pigment epithelium, and indeed pigment granules were $\frac{\mathbb{\Phi}}{\mathbb{Q}}$ seen floating free in the aqueous on several occasions. Sugar (1967), discussing pigmentary glaucoma, recognized this group of findings as constituting a "pigment dispersion syndrome" and considered pigmentary glaucoma to be a late feature of the syndrome. Certainly patient IVb shows no evidence of glaucoma at the present time, but now that his $\vec{\omega}$ life-expectancy has been prolonged by renal transplant it will be interesting to see whether he develops glaucoma in future years.

The previously reported ocular lesions of Alport's syndrome have affected the lens or its capsule and consequently the significance of the fundus appearances described above if remains in doubt, particularly in view of the equivocal ERG results, and whether a typical tapeto-retinal degeneration develops in the future remains to be seen.

Crawfurd and Toghill (1968) discussed the possible reasons for the relatively small $\vec{\square}$ number of cases, approximately I 5 per cent., of Alport's syndrome in which ocular involve-c ment has been noted. Although failure to recognize ocular lesions, particularly the less $\stackrel{\leftarrow}{\rightarrow}$ marked changes, cannot alone explain this deficiency, it seems probable that a number $\vec{\varphi}$ could be accounted for in this way. In support of this contention, it may be noted that $\stackrel{0}{0}$ the young male IVe was asymptomatic and that the ocular lesion (anterior lenticonus) was diagnosed only after slit-lamp examination, the ophthalmoscopic appearances being normal. Secondly, even his severely affected brother IVb considered his visual acuity to be normal at $6 / 24$ in each eye, presumably because he had grown up to accept such $\frac{\mathscr{D}}{D}$ vision as normal. Consequently, if Alport's syndrome is not suspected from the family $\stackrel{\varrho}{\Rightarrow}$ history, it is unlikely that the milder ocular abnormalities will be detected on routine $\frac{9}{3}$ medical examination and even patients with well-marked lesions cannot be relied upon to volunteer symptoms referable to the eyes.

(2) GENETIC DEFECT

The limited number of generations with affected individuals in this family precludes any fresh conclusions being drawn as to the mode of inheritance of the disease. It is probable that the initial mutation occurred in patient IIIa, since the members of the previous generations, maternal and paternal, all either died in old age of apparently unrelated causes $ᄋ$ or are still alive. Crawfurd and Toghill (1968) brought the pedigree of Alport's original $\frac{D}{0}$ family up to date, and noted that the condition tended to die out after a few generations. However, now that renal dialysis and transplantation offer even the most severely affected $\circlearrowleft$ individuals a reasonable life-span and the possibility of raising a family, this tendency may be reversed.

\section{Summary}

The clinical features of a "pigment dispersion syndrome" with possible retinal degeneration in addition to the usual features of the disease are described in a member of a previously unreported family with Alport's syndrome.

I should like to thank Mr. J. R. Hudson and Dr. S. Cameron for permission to publish this report on patients under their care: and for helpful advice. 


\section{References}

ALPORT, A. C. (1927) Brit. med. F., 1, 504

ARNotT, e. J., CRAWford, M. D'A., and toghill, P. J. (1966) Brit. F. Ophthal., 50, 390

GRAWFURD, M. D'A., and TOGHILl, P. J. (1968) Quart. F. Med., n.s. 37, 563

PERKoff, G. T., NUGENT, C. A., JR., DOLOWITZ, D. A., STEPHENS, F. E., GARNES, W. A., and TYLER, F. H. (1958) Arch. intern. Med., 102, 733

Shaw, R. F., and Glover, R. A. (196r) Amer. F. hum. Genet., 13, 89

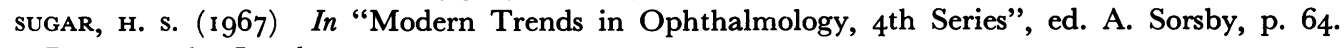

Butterworths, London 